|| ISSN(online): 2589-8698 || ISSN(print): 2589-868X ||

International Journal of Medical and Biomedical Studies

Available Online at www.ijmbs.info

NLM (National Library of Medicine ID: 101738825)

Index Copernicus Value 2019: 79.34

Original Research Article

Volume 5, Issue 8; August: 2021; Page No. 290-292

\title{
COMPARISON OF LOCAL VERSUS SPINAL ANAESTHESIA IN INGUINAL HERNIA REPAIR
}

\author{
${ }^{1}$ Dr Dharmpal Godara, ${ }^{2}$ Dr Mamta Choudhary
}

${ }^{1}$ MBBS, MS, Department of General Surgery, Govt. S.K. Medical College, Sikar (Rajasthan)

${ }^{2}$ MBBS, MS, Department of Obstetrics \& Gynaecology, Govt. S.K. Medical College, Sikar (Rajasthan)

Article Info: Received 05 July 2021; Accepted 18 August 2021

DOI: https://doi.org/10.32553/ijmbs.v5i8.2053

Corresponding author: Dr Mamta Choudhary

Conflict of interest: No conflict of interest.

\section{Abstract}

Background: To determine whether local anaesthetic technique is an acceptable alternative to spinal anaesthesia for hernia repair, especially with regards to operative conditions, postoperative pain relief and complications.

Methods: This was a prospective randomized clinical study consisting of 100 patients. The patients posted for tension free lichtenstein elective hernioplasty were allocated to either of two groups, group A ( $\mathrm{n}=50)$ were given local anaesthesia and patients in group $B(n=50)$ were given spinal anaesthesia.

Results: There was no demographic difference between the two groups. Time taken in local anesthesia was higher than spinal anesthesia. Intraoperative pain was higher in local anesthesia than spinal anesthesia.

Conclusions: We concluded that local anaesthesia can be a preferred method in day-case hernia surgeries owing to its advantages of ease of administration and less complications.

Keywords: Day-case surgery, Inguinal hernia, Local anaesthesia, Spinal anaesthesia

\section{Introduction}

Inguinal hernia repair is one of the most commonly performed operations world-wide, can be done under general anaesthesia, spinal or epidural anaesthesia and local anaesthesia depending upon a variety of factors viz. surgeon's wish, patient's acceptance, safety, feasibility and cost, etc. ${ }^{1}$ Recently there has been revival in the use of local anaesthetic technique for hernioplasty.

Patient safety should be the paramount factor in choosing the type of anesthesia. General or spinal anesthesia are still the most common types of anesthesia being used in India. ${ }^{2}$ Studies comparing the recovery profiles of local, general and regional anesthesia show that local anesthesia is ideal for day care surgery. ${ }^{3}$

The present study was designed to determine whether local anaesthetic technique is an acceptable alternative to spinal anaesthesia for hernia repair, especially with regard to operative conditions, patient's and surgeon's satisfaction, postoperative pain relief as well as complications.

\section{Material and Methods}

We included 100 patients of either sex with ASA physical status I-II with age of more than 10 years having uncomplicated inguinal hernia. Patients with recurrent, bilateral, irreducible, strangulated, incarcerated, obstructed hernia, obese patients were excluded in this study. By simple randomization, patients were divided into two groups;

Group A-Receiving local anaesthesia (LA) with 2\% xylocaine with adrenaline 4-6 $\mathrm{mg} / \mathrm{kg}(\mathrm{n}=50)$

Group B-Receiving spinal anaesthesia (SA) with $0.3 \mathrm{mg} / \mathrm{kg}$ in adults and $0.4 \mathrm{mg} / \mathrm{kg}$ in children of $0.5 \%$ bupivacaine $(\mathrm{n}=50)$

A written informed consent was obtained from patients and data was collected on printed proforma including age, gender, and occupation, history of swelling in inguinal region, COPD, jaundice, previous abdominal surgery, obesity and concomitant diseases.

\section{Results}

Mean age in group A was $45.36 \pm 2.39$ years and $48.25 \pm 2.37$ years in group B ( $p$ value $>0.05$ ).

Table 1: General characteristic

\begin{tabular}{|l|l|l|l|l|}
\hline \multicolumn{2}{|l|}{ Variable } & Group- A & Group- B & p-value \\
\hline Operative time & $63.25 \pm 6.35$ mint. & $56.39 \pm 7.12$ mint. & $>0.05$ \\
\hline \multirow{4}{*}{ VAS } & Intra-operative & $5.32 \pm 2.21$ & $0.00 \pm 0.00$ & $<0.01$ \\
\cline { 2 - 5 } & At 12 hours & $4.32 \pm 0.91$ & $4.40 \pm 0.93$ & $>0.05$ \\
\cline { 2 - 5 } & At 24 hours & $3.42 \pm 0.84$ & $3.46 \pm 0.88$ & $>0.05$ \\
\cline { 2 - 5 } & At 48 hours & $1.24 \pm 0.25$ & $1.26 \pm 0.28$ & $>0.05$ \\
\hline \multicolumn{2}{|l|}{ Mean time taken by patient to become ambulatory } & $0.00 \pm 0.00$ & $6.21 \pm 1.23 \mathrm{hrs}$ & $<0.01$ \\
\hline
\end{tabular}


In the present study the mean operative time was $63.25 \pm 6.35$ minutes in group A and $56.39 \pm 7.12$ minutes in group B. The difference between the time taken to complete operation under LA group was not statistically significant to the time taken in SA group ( $\mathrm{p}$ value $>0.05$ ). Intraoperative pain was assessed by using Visual Analog Scale (VAS). VAS difference in both groups was found statistically insignificant. Patients in local anaesthesia group were ambulatory immediately after surgery as no sedation was given to the patients while patients in the spinal anaesthesia group were ambulatory after almost 6 hours after surgery (mean time $=6.21$ hours). Recovery from anesthesia was significantly faster ( $\mathrm{p}$ value $<0.01$ ).

Table 2: Complication

\begin{tabular}{|l|l|l|}
\hline Complication & Group- A & Group- B \\
\hline Wound hematoma & 1 & 3 \\
\hline SSI & 2 & 2 \\
\hline Urinary retention & 0 & 4 \\
\hline Recurrance (after 4wks) & 0 & 0 \\
\hline Pain after 1wk & 3 & 4 \\
\hline
\end{tabular}

\section{Discussion}

Local anaesthesia can be the choice of anaesthesia for all reducible adult inguinal hernia repairs. It is safe, simple, effective, and economical, without post-anesthesia side effects. ${ }^{4}$ The inguinal region, which includes the inguinal canal, the spermatic cord and the surrounding soft tissue structures, receives its sensory innervation from three nerves-iliohypogastric nerve, ilioinguinal nerve, and genitofemoral nerve. The ilioinguinal nerve passes through the external inguinal ring, usually in close association with the spermatic cord. The genitofemoral nerve $(\mathrm{L} 1,2)$ supplies inguinal cord structures and the anterior scrotum via its genital branch and supplies the skin and subcutaneous tissues of the femoral triangle via the femoral branch. These nerves, and other adjacent nerves providing overlapping sensory supply, are the targets of the inguinal regional block. The local anaesthesia produces skin anaesthesia in the line of the incision. It also produces anaesthesia of the parietal peritoneum of the hernia and especially the neck of the sac which is very sensitive. Additionally, local anesthesia administered before the incision produces longer postoperative analgesia. It is because local infiltration, theoretically, inhibits build-up of local nociceptive molecules and, therefore, there is better pain control in the postoperative period. $^{5}$

In the present study, patients with LA had more pain intraoperatively as compared to group who received SA. This can be attributed to the fact that pain during operation is felt in case of large hernia operated under local anesthesia, if dissection is difficult due to adhesions of the sac. ${ }^{6}$ Studies done by Song et al and Amid et al demonstrated that conversion of local anesthesia to general anesthesia was because of pain during dissection or reposition of the hernia sac supporting our study. ${ }^{7,8}$

In the present study, post-operative pain was recorded at 12 , 24 and 48hours after operation by using VAS and was slightly lower in LA group. These results were comparable to other studies conducted by Song et al which showed that VAS scores were lower in patients operated under local anesthesia compared to patients operated under spinal anesthesia. ${ }^{7}$ O'Dwyer et al also observed that the patients in the LA group had significantly less pain on movement at 6hours postoperatively. ${ }^{8}$ Callesen et al derived from their study that LA provides a safe alternative to other anesthetic techniques with an acceptable rate of satisfaction, but intraoperative pain relief needs improvement. ${ }^{5}$

\section{Conclusion}

It can be reliably concluded that local anaesthesia is a feasible and effective method for inguinal hernia repair in adults comparable to spinal anaesthesia as far as patient satisfaction in terms of duration of surgery, postoperative pain, complications related to spinal anaesthesia, recovery from anaesthesia (early postoperative ambulation), length of hospital stay are concerned. Therefore, local anaesthesia can be another good choice for inguinal hernia repair, but it can't be confirmed that local anaesthesia is better than spinal anaesthesia. We also recommend further studies with larger groups to authenticate our study results.

\section{References}

1. Goel A, Bansal A, Singh A. Comparison of local versus spinal anesthesia in long standing open inguinal hernia repair. Int Surg J. 2017; 11:3701-4.

2. Bhedi A, Damor S, Sarkar A. Inguinal hernia repair:Comparison of local anaesthesia and spinal anaesthesia. JMSCR. 2016; 12:14540-7.

3. Van Veen RN, Mahabier C, Dawson I, Hop WC, Kok NF, Lange JF, Jeekel J. Spinal or local anesthesia in Lichtenstein hernia repair: a randomized controlled trial. Ann Surg. 2008; 247(3):428-33.

4. Russell RH: The saccular theory of hernia and the radical operation. Lancet. 1906; 168(4340):1197203.

5. Callesen $\mathrm{T}$, Bech $\mathrm{K}$, Kehlet $\mathrm{H}$. One thousand consecutive inguinal hernia repairs under unmonitored local anaesthesia. Anesth Analg. 2001; 93:1373-61.

6. Nordin P, Zetterström H, Gunnarsson U, Nilsson E. Local, regional, or general anaesthesia in groin hernia repair: multicentre randomised trial. Lancet. 2003; 362(9387):853-8. 
7. Song D, Greilich NB, White PF, Wateha MF, Tongier WK. Recovery profiles and costs of anaesthesia for outpatient unilateral inguinal herniorrhaphy. Anesth Analg. 2000; 91:876-81.
8. O’ Dwyer PJ, Serpell MG, Millar K, Paterson C, Young D, Hair A, Courtney CA, et al. Local or general anaesthesia for open hernia repair. A randomized trial. Annals Surg. 2003; 237:574-9. 